\title{
Method for optimizing the number of glass-fiber reinforced plastic rebars in concrete structures
}

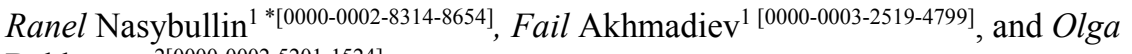 \\ Bakhareva ${ }^{2[0000-0002-5201-1524]}$ \\ ${ }^{1}$ Kazan State University of Architecture and Engineering, 420043 Zelenaya st., Kazan, Russia \\ ${ }^{2}$ Kazan State Agrarian University, 420015 Karl Marks st., Kazan, Russia
}

\begin{abstract}
Innovations in the construction industry have led to a change in the technological structure, the use of end-to-end technologies, innovative materials, information management and the need for new technical, technological and managerial solutions. The research problem is the optimal placement of glass-fiber reinforced plastic bars in concrete structures. It took several steps to solve the research problem: 1) development of an algorithm for solving the design problem in TEKLA Structures; 2) performing of calculations based on the finite element method in LIRA-SAPR, which were further reproduced in Rhinoceros and Grasshopper (based on interoperability in a single BIM environment); 3) implementation of the optimization algorithm using the parametric optimization method; 4) A practical calculation of determining the optimal values of the loads of glass-fiber reinforcement in the slab on the example of a typical design problem of a structural element of a construction facility; 5) calculation of positive economic effect. The conclusion is that the algorithm can be used in the practice of building design.

Keywords: innovation, reinforcing bars, glass-fiber reinforced plastic, BIM, interoperability, end-to-end technologies, finite element method, object lifecycle, information management, Grasshopper, Rhinoceros, LIRA-SAPR, TEKLA Structures.
\end{abstract}

\section{Introduction}

The concept of the circular economy is the optimal consumption of natural resources, applied to such spheres as the construction industry, the greening of construction production, the reduction of energy intensity, the improvement of energy efficiency of facilities, the use of local materials, the reuse and harmless disposal of building materials. The competitive advantage of a company in the construction industry is, all other things being equal, a reduction in the number and weight of materials used in construction [1,2]. To increase competitiveness, companies invest in new production technologies, materials, and waste reduction methods, which allows reducing the total cost of the investment project and obtaining a significant economic effect on the implementation of construction projects $[3,4]$. Due to the high level of development of computer technology in construction,

\footnotetext{
${ }^{*}$ Corresponding author: nasybullin.ranel@gmail.com
} 
complex structures are calculated using software, resulting in a cost-effective method of designing buildings and structures [5-7].

Optimization methods allow the designer to make a choice from a set of possible solutions to an engineering problem and make an optimal decision, reducing the project development period. In practice, optimization problems are solved using universal software such as MATLAB, Octave, Scilab, Dakota, Solver and other software systems [2, 6]. At the same time, the universal software for solving optimization problems is not fully suitable for solving particular industry-specific problems of designing facilities in construction, created in the form of computer graphic three-dimensional, parametric objects using Building Information Modelling (BIM).

BIM provides significant advantages when creating computer models of construction facilities. They are fast collision detection, automatic algorithms of regulatory design validation, augmented and virtual reality visualization, and collaboration methods [8-12]. Currently implemented investment construction projects based on BIM are being improved and, thanks to the development of national standards and state information systems, are striving to full automation of business processes of construction industry firms [13-15]. Of particular relevance are the studies on the implementation of interoperability principle for the work of related parties to the investment project, providing end-to-end design technology in different software environments. The solution of the problem of optimizing the lengths of reinforcing bars is possible in the "Grasshopper» software, which has access to both quantitative and spatial data about the design object, which makes it easier to solve the problem of design optimization. "Grasshopper» supports the principles of BIM and allows transferring data to other software systems based on BIM [16-21].

Currently, reinforced concrete elements are traditional main structural materials of buildings and structures for various purposes. They bear the load throughout the entire life cycle of the building (structure), they must be reliable, durable and affordable. The use of traditional reinforced concrete structures in construction is being actively studied. The main tasks for optimizing the already proven structural solutions of reinforced concrete structures have been solved, and the prospects for the development and application of innovative materials are being supplemented [22-23].

Reinforcement in reinforced concrete structures is mainly used for the ability to perceive the tensile forces and strengthen the concrete of the compressed areas of the structures. The ability to bear the tensile load of the reinforcement is determined by its physical and mechanical characteristics, such as yield strength and elastic modulus, obtained during tests [24-26]. It is established that if a transverse reinforcement is installed in a compressed element that can effectively hold transverse deformations, it is possible to increase significantly its load-bearing capacity. It is experimentally determined that concrete has an increased compressive resistance within the core enclosed from the inside of the transverse reinforcement. When flexible reinforcement bars are compressed, the reinforcement bars tend to lose their stability long before the ultimate strength is exhausted, and can subsequently destroy the protective layer of concrete, which in turn contributes to the premature destruction of structures. To avoid such an unsafe phenomenon, transverse reinforcement should be installed. Transverse reinforcement holds the transverse deformations of concrete that can occur during longitudinal compression, which leads to an overestimated resistance of concrete to longitudinal compression, as well as the subsequent appearance of the first longitudinal cracks in the concrete [27-29].

The use of innovative material - non-metallic fiberglass reinforcement as compressed non-prestressed reinforcement - instead of traditional steel reinforcement in reinforced concrete elements increases the corrosion resistance of compressed elements operated in aggressive environments, which provides an economic effect of innovation by reducing the cost of the material during the life cycle of the construction facility, including operating 
costs. Fiberglass reinforcement, due to its low cost compared to other types of non-metallic reinforcement, can be used as a replacement for steel in concrete structures [26, 30].

Glass fiber copes with high tensile stress, but due to its brittleness, it cannot withstand compression. Plastic is good at handling compression loads, but it cannot withstand high tension. Fiberglass-reinforced plastic, combining fiberglass and plastic, becomes a material that resists both compressive and tensile influences well. Glass fibers have evolved as the main reinforcing materials for a range of composite materials, and recent developments show high potential for a variety of applications, as increased erosion resistance, higher tensile strength, impact resistance, and other mechanical properties can now be imparted to composites [31-33].

The main advantages of fiberglass reinforcement are: resistance to humidity, weather conditions, thermal effects; good insulation and sound absorption; absence of rust, radioactive elements; protection against aging, fire resistance and good temperature characteristics of the products. Fiberglass can be used both in the wet and warm south, and in the dry and cold north $[25,28]$.

Fiberglass has the following main advantages: standardized production, low specific gravity, high tensile strength, corrosion resistance, high thermal conductivity, low cost, which contributes to the introduction of fiberglass reinforcement in construction. There is a contradiction, on the one hand, the positive qualitative effect of the use of new materials and technologies in construction, on the other hand, the lack of experience and practice in solving economic and mathematical problems of optimizing the placement of rebar to reduce the cost of using new technologies. Previously, we investigated the problems of optimal placement of traditional steel reinforcement in slabs and proposed an algorithm [34]. In this study, we use the developed algorithm to solve the optimization problem with an innovative material - glass-fiber reinforced plastic and its adaptation for a new building material.

The aim of the study is to optimize the number of standard sizes of glass-fiber reinforced rebars in concrete structures (floors/coverings).

Main research objectives:

1) development of an algorithm for optimizing the number of glass-fiber reinforced plastic rebars in concrete structures;

2) testing the performance of the modified algorithm on an application example based on the interoperability principle.

\section{Materials and methods}

The finite element method (FEM) is a general numerical method for solving partial differential equations to solve a problem. FEM divides a large system into smaller and simpler parts, called finite elements, used to perform Finite element analysis (FEA) of any given physical phenomenon.

According to the data of the task, the calculation was made in the software package "LIRA-SAPR» using the finite element method; the loads are classified into 2 types, longitudinal and transverse reinforcement in the slabs, the table (Table 1) shows the longitudinal reinforcement named Reinforcement 1 and Reinforcement 2 , and the transverse one named Reinforcement 3 and Reinforcement 4 . The calculations of the slab are exported from «LIRA-SAPR», and the table (Table 1) records the loads on the reinforcement in the elements performed by the FEM method in CSV format.

In addition to the table (Table 1), one more table is exported, which contains elements with the coordinates of each point with a link to the table (Table 1). Having access to the coordinate table, it is possible to recreate the geometry and perform the required calculations on the loads in the rebar and assign their value to each element. 
Table 1. Table of elements, with assigned loads on rebars.

\begin{tabular}{|c|c|c|c|c|}
\hline Elements & Reinforcement $^{1}$ & Reinforcement $^{2}$ & Reinforcement $^{3}$ & Reinforcement $^{4}$ \\
\hline 170350 & 0.58 & 2.23 & 1.03 & 2.56 \\
\hline 170351 & 0.96 & 2.46 & 0.06 & 2.46 \\
\hline 170352 & 1.01 & 0.60 & 0.06 & 2.30 \\
\hline 170353 & 0.58 & 0.69 & 0.07 & 0.06 \\
\hline 170354 & 0.96 & 1.02 & 0.07 & 0.8 \\
\hline 170355 & 1.03 & 0.24 & 0.18 & 0.7 \\
\hline 170356 & 0.06 & 0.06 & 0.66 & 0.06 \\
\hline 170357 & 0.06 & 0.06 & 0.66 & 0.06 \\
\hline 170358 & 0.06 & 1.23 & 0.70 & 0.57 \\
\hline 170359 & 0.90 & 0.20 & 0.70 & 0.50 \\
\hline 170360 & 0.90 & 6.21 & 0.06 & 0.06 \\
\hline 170361 & 0.06 & 6.21 & 0.06 & 0.94 \\
\hline 170362 & 0.06 & 1.21 & 0.06 & 0.35 \\
\hline 170363 & 0.06 & 1.21 & 0.06 & 0.35 \\
\hline
\end{tabular}

Source: authors' calculations

As a result of the study, calculations of glass-fiber reinforced plastic rebars were made in the software package «LIRA-SAPR» using the finite element method, then the data is converted to «Rhinoceros» with the «Grasshopper» plugin, and then the data and geometry are transferred from «Grasshopper» to «TEKLA Structures». All operations of data export / import and interaction of various software complexes were developed on the basis of the open BIM concept.

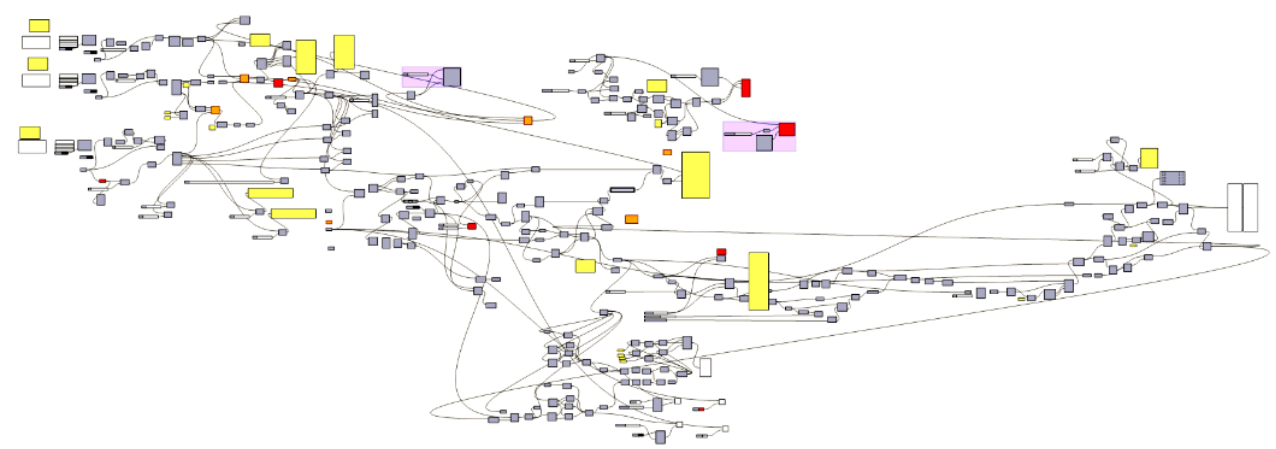

Fig. 1. Script in «Grasshopper» optimizes the amount of fiberglass reinforcement (authors ' algorithm).

On (Fig. 1) an algorithm is shown that first optimizes the amount of fiberglass reinforcement according to the data from the «LIRA-SAPR» tables, after optimization, the geometry is created based on the data in "Grasshopper» and a solid-state model with metadata is sent to "TEKLA Structures». The first step is to set up interaction with the «LIRA-SAPR» table with "Grasshopper», the connection is set up once, in the future, if you need to recalculate the model, you will only need to update the table. Next, the data is checked and optimized. The data is checked in the developed node, written in the C\# programming language. The developed node $b$ checks the data for possible errors and deletes them, reproducing the deleted items in the list. Another developed node optimizes the amount of fiberglass reinforcement. It is a modification of the algorithm that was previously developed to optimize steel reinforcement [34]. 


\section{Results}

When calculating the amount of glass-fiber reinforced plastic rebars in a concrete structure (slab), based on the calculations for a specific example performed in «LIRA-SAPR», we can conclude the following: the project uses an excessive amount of reinforcement bars. The developed modified algorithm in «Grasshopper» allows optimizing the number of glass-fiber reinforced plastic bars and offers to reduce the number of reinforcement bars with an indication of the optimal arrangement of the rods. At the same time, the algorithm leaves the same number of rods where the load on the elements varies within the required values. In elements where there is an exceedance beyond the required values with the nearest elements, a subsequent reinforcement is created. Similar actions occur for a homogeneous section, if the length of one reinforcing bar exceeds the limit value, a new reinforcing bar is created.

The mathematical model that optimizes the amount of fiberglass reinforcement is written in the $\mathrm{C} \#$ programming language and implemented in its own node.

\begin{tabular}{|c|c|c|c|}
\hline & $\{0\}$ & & $\{0\}$ \\
\hline 0 & 0 & 0 & 56.677027 \\
\hline 1 & 31.223983 & 1 & 56.677027 \\
\hline 2 & 108.859919 & 2 & 56.677027 \\
\hline 3 & 31.223289 & 3 & 56.677027 \\
\hline 4 & 108.859477 & 4 & 56.677027 \\
\hline 5 & 31.223289 & 5 & 56.677027 \\
\hline 6 & 108.859477 & 6 & 56.677027 \\
\hline 7 & 33.166782 & 7 & 56.677027 \\
\hline 8 & 142.026007 & 8 & 142.02578 \\
\hline 9 & 142.026121 & 9 & 142.02578 \\
\hline 10 & 142.025705 & 10 & 142.02578 \\
\hline 11 & 142.024242 & 11 & 142.02578 \\
\hline 12 & 142.026121 & 12 & 142.02578 \\
\hline 13 & 142.026146 & 13 & 142.02578 \\
\hline \multirow[t]{2}{*}{14} & 142.026121 & 14 & 142.02578 \\
\hline & $\{1\}$ & & $\{1\}$ \\
\hline 0 & 156.998188 & 0 & 112.451822 \\
\hline 1 & 147.306753 & 1 & 112.451822 \\
\hline 2 & 76.565744 & 2 & 112.451822 \\
\hline 3 & 61.740111 & 3 & 112.451822 \\
\hline 4 & 72.224285 & 4 & 112.451822 \\
\hline 5 & 159.875853 & 5 & 112.451822 \\
\hline 6 & 178.679628 & 6 & 166.093169 \\
\hline
\end{tabular}

Fig. 2. Load lists for each rebar (authors ' calculations).

Fig. 2 shows the load lists for each glass-fiber reinforced plastic rebar decomposed by the elements. The original list is on the left, the optimized list after using the modified algorithm is on the right. The criteria for averaging are set by the design engineer at the start of the calculations. For example, it is possible to reduce from 30 different types of glass-fiber reinforced plastic rebars to 7 , which will equally bear the load in the slab. After reducing the number of rods for each element, the values are rewritten, as well as checked for errors (Fig. 3). 


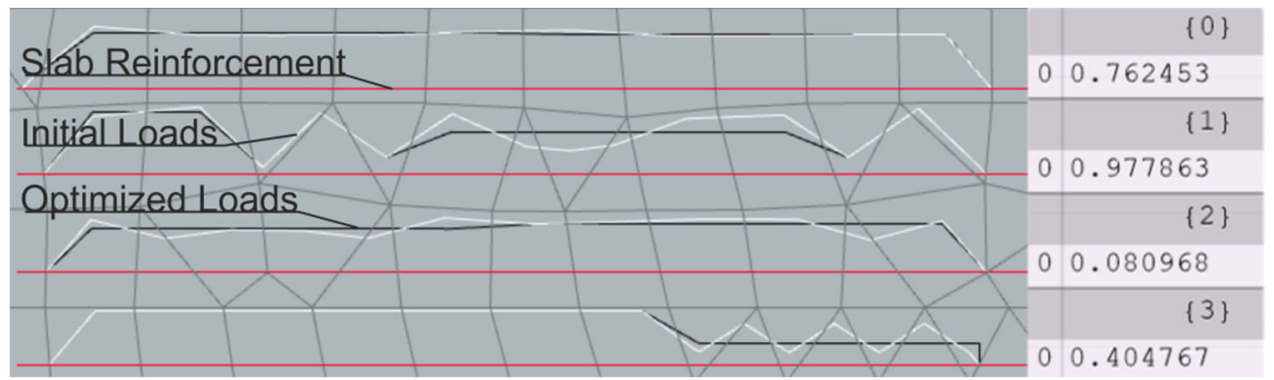

Fig. 3. Load graphs with the percentage of error of the optimizing algorithm (authors ' calculations).

Fig. 3 provides graphical information on the loads on glass-fiber reinforced plastic rebars in a concrete structure (slab). The gray curve is a concrete structure (slab) divided into many elements, created on the basis of data exported from LIRA-SAPR. The red line shows the cross-section of the reinforcement plate. The white graph shows the original loads, and the black graph shows the optimized loads. The figures on the right represent the percentage of error between the original and optimized graphs. The maximum number of 0.9 is the permissible error, but if the graph goes beyond the limit of 5 percent, you will need to review the criteria for calculating the averaging and recalculate everything again. In the next step, the geometry of the modeled object is recreated using the standard «Grasshopper» tools and the values of the reinforcement load are assigned to each element, and after all these actions, the solid-state model with the assigned data is transferred to the «TEKLA Structure» with the original components. "Grasshopper» and «TEKLA Structures» have a binding plugin that allows you to transfer data based on the concept of interoperability. The information model of the object includes slabs with reinforcement, the reinforcement contains load data and all data can be integrated, based on the data obtained, to refine the information model of the facility in «TEKLA Structures». If there are new slabs and you need to redo and recalculate the model, the recalculation process will take much less time.

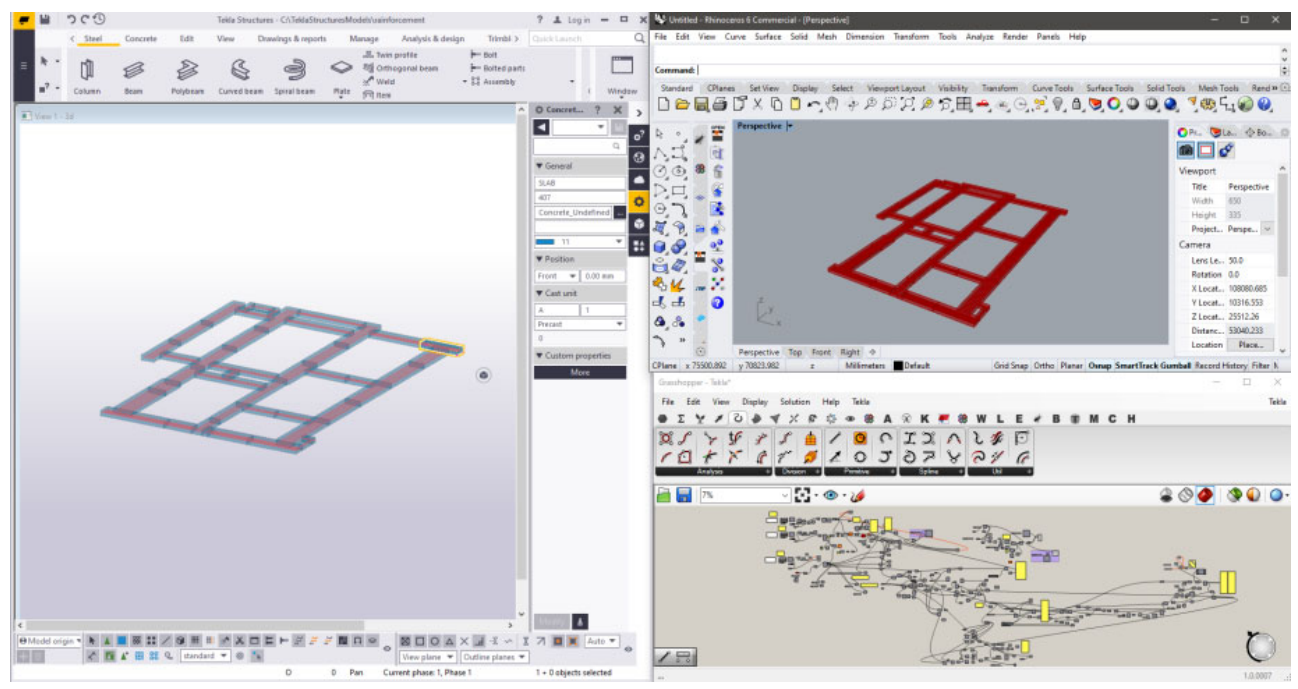

Fig. 4. Interaction of Tekla Structures, Rhinoceros, and Grasshopper programs (algorithm and model of authors). 
Fig. 4 shows the interaction of the software complexes «TEKLA Structures» and «Rhinoceros» in conjunction with «Grasshopper», a test information model in which «Grasshopper» built slabs with an optimized amount of glass-fiber reinforced plastic rebars according to data exported from «LIRA-SAPR». The slabs are first built in «TEKLA Structures», then loaded into "Grasshopper», using a developed script in the C\# programming language in «TEKLA Structures», which lays out the slabs.

\section{Discussion}

Based on the optimization algorithm for steel reinforcement in slabs [34], we modified the algorithm for glass-fiber reinforced plastic rebars in concrete structures, preserving the principles of the BIM concept and the interoperability of various software systems for engineering calculations in construction.

The development of the optimization algorithm was effectively carried out by means of visual programming in «Grasshopper» for further transmission of the graphical, parametric information BIM-model of the construction facility to other software calculation complexes.

Comparing the developed modified optimization algorithm with universal programs for solving optimization problems, it should be noted that visual programming tools are needed to solve optimization problems in construction, since the created real estate facility is described not only quantitatively, but also has a graphical essence and a reference on the ground, which is difficult and time-consuming to reflect in universal packages for solving optimization problems.

In the context of the application of a new end-to-end information modeling technology for objects in construction, the developed algorithm allows not only to quantify the need for rebar rods and make calculations, but also to create a solid-state digital model of the facility, save all its parameters during export/import operations to other BIM environments and implement a seamless business process of the investment project implementation stages, taking into account the industry specifics of the investment and construction complex.

\section{Conclusions}

1. A modified algorithm has been developed to optimize the number of glass-fiber reinforced plastic rebars in concrete structures (slabs), implemented by means of visual programming in «Grasshopper».

2. The task of optimizing the number of glass-fiber reinforced plastic rebars for a specific structural element of the building (slab) was set, the calculation was made by the method of parametric optimization, the calculations were carried out sequentially in different software packages based on the principle of interoperability of business processes and the implementation of end-to-end design technology. The error of the algorithm was $0.9 \%$, and the economic effect was $5 \%$.

\section{References}

1. S. K. Kim, W. K. Hong, J. K. Joo, Algorithms for Reducing the Waste Rate of Reinforcement Bars, Journal of Asian Architecture and Building Engineering, 3(1), 17 23 (2018) DOI: 10.3130/jaabe.3.17 
2. C. Zheng, M. Lu, Optimized Reinforcement Detailing Design for Sustainable Construction, Slab Case Study Procedia Engineering, 145, 1478-485 (2019) DOI: 10.3390/app9194127

3. O. V. Bakhareva, Strategic Planning of Infrastructure Development: BIM and Intelligent Building, Journal of Advanced Research in Law and Economics, 10, 8 (46), 2262-2270 (2019) DOI: 10.14505/jarle.v10.8(46).06.

4. O. Bakhareva, T. Azhimov, L. Azhimova, L. Marfina, A Khuzagaripov, The Classification of Transaction Costs: The Innovation in the Construction Industry Based on Building Information Modeling, A Case Study of Multilingual Schools, IOP Conf. Ser.: Mater. Sci. Eng., 890, 012118 (2020) DOI: 10.1088/1757-899X/890/1/012118

5. A. Porwal, K. N. Hewage, Building Information Modeling-Based Analysis to Minimize Waste Rate of Structural Reinforcement, J. Constr. Eng. Manag., 138, 943-954 (2017) DOI: 10.1061/(ASCE)CO.1943-7862.0000508

6. R. S. Correia, G. F. F Bono, G. Bono, Optimization of reinforced concrete beams using Solver, tool. Rev. IBRACON Estrut. Mater., 12, 4, 910-931 (2019) DOI: 10.1590/s1983-41952019000400011

7. M. Mangal, J. C. P. Cheng, Automated optimization of steel reinforcement in $R C$ building frames using building information modeling and hybrid genetic algorithm, Automation in Construction, 90, 39-57 (2018) DOI: 10.1016/j.autcon.2018.01.013

8. R. Jin, B. Zhong, L. Ma, A. Hashemi, L. Ding, Integrating BIM with building performance analysis in project life-cycle, Autom. Constr., 90, 39-57 (2018) DOI: 10.1016/j.autcon.2018.01.013

9. S. Hu, J. Wang, C. Hoare, Y. Li, P. Pauwels, J. O'Donnell, Building energy performance assessment using linked data and cross-domain semantic reasoning, Automation in Construction, 124, 103580 (2021) DOI: 10.1016/j.autcon.2021.103580

10. F. P. Rahimian, V. Chavdarova, S. Oliver, F. Chamo, OpenBIM-Tango integrated virtual showroom for offsite manufactured production of self-build housing, Autom. Constr., 102, 1-16 (2019) DOI: 10.1016/j.autcon.2019.02.009

11. R. Volk, J. Stengel, F. Schultmann, Building Information Modeling (BIM) for existing buildings - Literature review and future needs, Autom. Constr., 38, 109-27 (2014) DOI: 10.1016/j.autcon.2013.10.023

12. N. Knyazeva, D. Levina, Using BIM scenarios in operation services, Bull. Belgorod State Technol. Univ. named after. V. G. Shukhov, 4, 99-105 (2019) DOI: 10.34031/article_5cd6df471c80b0.92422061

13. S. Sen, The Impact of BIM/VDC on ROI Developing a Financial Model for Savings and ROI Calculation of Construction Projects, Department of Real Estate and Construction Management, 177, 58 (2018) DOI: oai:DiVA.org:kth-101167

14. S. Langar, Challenges with BIM Implementation: A Review of Literature college Students' Perception of Household Energy Efficiency View project Residential Industry Perception for Resilience View project, Automation in Construction, 95, 107-117 (2018) DOI: 10.1016/j.autcon.2018.06.009

15. S. Azhar, Building information modeling (BIM): Trends, benefits, risks, and challenges for the AEC industry, Leadersh. Manag. Eng., 11, 241-252 (2011) DOI: 10.1061/(ASCE)LM.1943-5630.0000127

16. R. Santos, A. A. Costa, J. D. Silvestre, L. Pyl, Integration of LCA and LCC analysis within a BIM-based environment, Autom. Constr., 103, 127-149 (2019) DOI:10.1016/j.autcon.2019.02.011

17. J. Choi, I. Kim, A methodology of building code checking system for building permission based on open BIM ISARC 2017, Proceedings of the 34th International Symposium on Automation and Robotics in Construction, International Association for 
Automation and Robotics in Construction (I.A.A.R.C), 945-950 (2017) DOI: 10.22260/ISARC2017/0131

18. J. Choi, I. Kim, A Methodology of Building Code Checking System for Building Permission based on open BIM, 2017, in Proceedings of the 34rd ISARC, 945-950 (2017) DOI: 10.22260/ISARC2017/0131

19. J. Choi, I. Kim, Development of openBIM-based Interoperability System for Code Checking System, Science \& Engineering Research Support Society, 10, 8, 99-110 (2017) DOI: 10.14257/ijunesst.2017.10.8.10

20. L. H. Yang, L. Xu, W. C. Wang, S. H. Wang, Building Information Model and Optimization Algorithms for Supporting Campus Facility Maintenance Management: A Case Study of Maintaining Water Dispensers, KSCE J. Civ. Eng., 25, 12-27 (2021) DOI: 10.1002/adhm.202100335

21. S. Abrishami, J. Goulding, Generative BIM workspace for AEC conceptual design automation: Prototype development, Engineering, Construction and Architectural Management, 28, 2, $482-509$ (2021) DOI: 10.1108/ECAM-04-2020-0256

22. E. A. Efimenko, M. Y. Bekkiev, D. R. Mayilyan, A. S. Chepurnenko, Determination of the optimal distribution of supports in the floor slabs of in-dustrial buildings using stochastic methods, Her. Dagestan State Tech. Univ. Tech. Sci., 47, 138-146 (2020) DOI: $10.21822 / 2073-6185-2020-47-1-138-146$

23. A. Lapshinov, Prospects of potential application of non-metallic frp reinforcement in frp-reinforced concrete compressive members as main longitudinal non-prestressed reinforcement, Vestn. MGSU, 10, 96-105 (2015) DOI: 10.22227/19970935.2015.10.96-105

24. M. Z. Afifi, H. M. Mohamed, B. Benmokrane, Axial Capacity of Circular Concrete Columns Reinforced with GFRP Bars and Spirals, J. Compos. Constr., 18, 04013017 (2014) DOI: 10.1007/s13369-020-04881-0

25. S. A. A. Jabbar, S. B. H. Farid, Replacement of steel rebars by GFRP rebars in the concrete structures Karbala, Int. J. Mod. Sci., 4, 216-227 (2018) DOI:10.1016/j.kijoms.2018.02.002

26. A. Avdeeva, I. Shlykova, M. Antonova, Y. Barabanschikov, S. Belyaeva. Reinforcement of concrete structures by fiberglass rods, MATEC Web of Conferences, 53, 01006 (2016) DOI: 10.1051/matecconf/20165301006

27. S. Stepanov, N. Morozov, N. Morozova, D. Ayupov, D. Makarov, D. Baishev. Efficiency of use of galvanic sludge in cement systems, Procedia Engineering, 165, 1112-1117 (2016) DOI: 10.1016/j.proeng.2016.11.827

28. S. H. Alsayed, Y. A. Al-Salloum, T. H. Almusallam, Performance of glass fiber reinforced plastic bars as a reinforcing material for concrete structures, Compos. Part B, Eng., 31, 555-67 (2020) DOI:10.1.1.487.5910

29. Y. Barabanshchikov, S. Belyaeva, A. Avdeeva, M. Perez, Fiberglass Reinforcement for Concrete, Appl. Mech. Mater., 725-726, 475-80 (2015) DOI: 10.4028/www.scientific.net/AMM.725-726.475

30. Y. Z. Wang, A. Kanvinde, G. Q. Li, Y. B. Wang, A new constitutive model for high strength structural steels, J. Constr. Steel Res., 182 (2021) DOI: 10.1016/j.jcsr.2021.106646

31.S. Qian, X. Liu, Y. Ye, Q. Xu, T. Zhang, X. Li, Effect of gap and overlap fiber placement defects on the delamination behavior of L-shaped composite laminates, Composite Structures (IF 5.138), 113963 (2021) DOI: 10.1016/j.compstruct.2021.113963

32. K. Delavari, H. Dabiryan, Mathematical and numerical simulation of geometry and mechanical behavior of sandwich composites reinforced with 1×1-Rib-Gaiting weft- 
knitted spacer fabric, Compressional behavior Compos. Struct., 113952 (2021) DOI: 10.1016/j.compstruct.2021.113952

33. B. Basaran, I. Kalkan, E. Bergil, E. Erdal, Estimation of the FRP-Concrete Bond Strength with Code Formulations and Machine Learning Algorithms, Compos. Struct., 113972 (2021) DOI: 10.1016/j.compstruct.2021.113972

34. R. Nasybullin, F. Akhmadiev, O. Bakhareva, The optimization of the number of reinforcing bars in the slabs in Grasshopper and integration with TEKLA and LIRA$S A P R$, IOP Conference Series: Materials Science and Engineering, 890, 012123 (2020) DOI: $10.1088 / 1757-899 X / 890 / 1 / 012123$ 